\title{
En busca de la belleza, entre espejismo(s) y eficacia(s). El impacto de la publicidad para productos cosméticos adelgazantes: El rol moderador de las estrategias de comparación social ${ }^{1}$
}

\section{In search of beauty, between illusion(s) and efficiency(ies). The impact of advertising for cosmetic slimming products: The moderating role of social comparison strategies}

\author{
Miruna Radu \\ Advancia, CCIP \\ mradu@advancia-negocia.fr
}

\section{Mihaela Oprescu}

Universidad de Paris III, Sorbonne Nouvelle

mihaela.oprescu@univ-paris3.fr

\section{Resumen}

El artículo discute el modo en que los discursos mediáticos, especialmente los publicitarios, construyen ciertos imaginarios sobre el cuerpo que, desde una perspectiva psicosocial, tienen impacto en el modo como las audiencias perciben su propia corporalidad. A través del examen de un caso -sobre la construcción de la imagen del cuerpo femenino-se examinan las estrategias de comparación social desplegadas a propósito de estos modelos mediáticos de cuerpo y cómo estos inciden en las definiciones identitarias y de género de las audiencias femeninas.

Palabras clave: Publicidad, cuerpo, comparación social, género.

\section{Abstract}

The article discusses how media discourse, particularly advertisers, build some imaginary on the body that, from a psychosocial perspective, have an impact on the way audiences perceive their own physicality. Through the examination of a case-about the construction offemale body image-there are examinetes the social comparison strategies deployed about these body media models and how these definitions affect gender identity and female audiences.

Keywords: Advertising, body, social comparison, gender.

4. Traducido desde el francés por Lorena Antezana Barrios. 


\section{Introducción}

«Lo Bello no es nada más que el inicio de lo Terrible» Rainer Maria Rilke

Françoise Dolto $(1961,1984)$ pensaba que la imagen del cuerpo es del orden fantasmático, « fuera del lugar y fuera del tiempo, puro imaginario y expresión de las inversiones de la líbido ». Memoria de una vivencia imaginaria subjetiva, la imagen del cuerpo es el lugar geométrico del encuentro entre imaginario social e imaginario individual. Construcción fantasmática del individuo, el cuerpo percibido conlleva así las trazas de los fantasmas del conjunto social, siendo el cuerpo el símbolo utilizado por la sociedad para hablar de sus fantasmas (Bernard, 1995) ...

\section{De la $\ll$ Belleza Posible $»$ a la $\ll$ Belleza Obligatoria $»$}

El mito actual de la incesante metamorfosis voluntaria del cuerpo y su corolario, la creencia en la exterioridad del cuerpo en relación a la voluntad activa del individuo, se remontan al alba de la modernidad : «como un reloj compuesto de ruedas y contrapesos considero el cuerpo del hombre», declaraba Descartes ${ }^{2}$. Objeto de búsquedas y de obsesiones, negado, instrumentalizado, abolido y reconstruido, el cuerpo - lugar de inversión emocional, financiera y axiológica, verdadero emblema de sí - es quizás uno de los primeros espacios de control social de las sociedades occidentales actuales... Pues la sociedad posmoderna exije que el individuo se conforme con las normas, al mismo tiempo que le recuerda afirmarse en tanto ser libre, de realizarse, de ser feliz: « la normalización postmoderna se presenta siempre como el único medio de ser realmente uno mismo, joven, esbelto, dinámico» (Lipovetsky, 1983 : 70). Sé tú mismo, esta prescripción paradójica del conformismo presentada como un medio de afirmación de sí (Raveneau, 2000) manifiesta su presencia explícita o implícita en los discursos mediáticos, las imágenes publicitarias, las representaciones y las prácticas sociales actuales.

5. Descartes, R. (1970) Méditations métaphysiques. Paris : Presses Universitaires de France. Según él, ontológicamente, el individuo estaría dividido en dos partes autónomas y heterogéneas, el cuerpo y el espíritu. Objeto de investigaciones, afectado por un índice depreciativo, el cuerpo es una « frontera del sujeto » (Le Breton, 1990: 71), Descartes refusándole toda identificación : « yo no soy en absoluto ese conjunto de miembros que llaman el cuerpo humano » (Descartes, 1970 : 202). Pero la invención del cuerpo moderno pertenece en principio a los primeros anatomistas que, a partir de Vesale (1543, De Humani Corporis Fabrica), han puesto las bases de una mutación epistemológica llegando a la medicina contemporánea. Indice fundamental de la emergencia del individualismo, la constitucion del saber anatómico en la Italia del Quattrocento, en las Universidades de Padua, de Venecia, de Florencia, representa un momento clave del individualismo occidental : con las primeras disecciones oficiales, a principios del XVo siglo, después su banalización durante los XVIo-XVIIo siglos, la distinción cuerpo/ espíritu encuentra sus fundamentos científicos. 
El más bello objeto de inversión individual (Baudrillard, 1970 : 2000), el cuerpo se impone hoy día como un lugar de predilección del discurso social. En efecto, el «deber de aparecer disfrazado en derecho al bienestar» (Perrot, 1984 : 205) impone a cada uno un trabajo de observación y de control sistemático de su apariencia física. El corporismo actual es el signo de un proceso de transformación del cuerpo en otro sí mismo, estando los individuos llevados a utilizar su imagen para expresar y afirmar su identidad (Chabrol, 1971).

A la vez materialidad e imaginario, el cuerpo consagrado por el discurso mediático y notoriamente por la publicidad, es el lugar de la maniquí. Creación de las industrias de la moda, la modelo (del nerlandes manne-ken, « hombre pequeño ») es la concretización del cuerpo femenino ideal de la segunda mitad del XXo siglo. B. Vacker (1993) piensa que la legitimidad de las publicidades actuales está fundada en la teoría estética de la « belleza posible $»$ : a diferencia de la teoría estética de la « belleza imposible », que, según Platon, concebía la belleza como un principio trascendente intangible, la teoría de la «belleza posible » afirma, en la continuidad de Aristóteles, que la belleza es un principio inmanente al mundo sensible, un atributo que los hombres pueden esperar adquirir. De la belleza posible a la belleza obligatoria, no hay más que una etapa que atravesar.... Pues si la belleza existe aquí-abajo, se vuelve entonces posible para cada uno de nosotros llegar a ella, con la ayuda de productos y de técnicas de cuidado apropiados. Y si es realmente posible ser bello, es necesario entonces que cada uno intente serlo ... Es por este abuso lógico que el discurso social ambiente transforma lo posible de la belleza en la obligación de belleza. Frente a las proposiciones y a las prescripciones sociales, las mujeres conservan sin embargo una cierta libertad: el cuerpo percibido no es el simple resultado de las obligaciones sociales, las mujeres podrían controlar su ajuste personal a las normas, elegir su grado de inversión en el juego social de las puestas en escena de sí. Entre la definición de sí por oposición y, respectivamente, la definición de sí por identificacion, la imagen del cuerpo constituye un compromiso re-negociado cada vez entre sí y los otros.

\section{El impacto de las imágenes femeninas idealizadas, según los fines perseguidos: el rol moderador de la comparación social.}

La Mujer en la publicidad, es la mujer de la Utopía. Lisa, perfecta, siempre joven y sonriente, plena de vida, sana, fina, sin cicatrices, sin manchas, sin la menor várice, su rostro sin ninguna arruga, sus piernas sin la sombra de la celulitis, feliz, pura, impecable, purgada de las contingencias del cotidiano. « Hija de la alquimia » (Lauzon, 2000), la imagen fotográfica convierte a la puesta en escena fantasmática del cuerpo femenino ideal en ilusión de lo real. En efecto, la recepción ${ }^{3}$ de las imágenes publicitarias parece mantener relaciones de estrecho parentesco con mecanismos cognitivos tratando la información perceptiva. En la medida en

6. «Una imagen bidimensional que no es recibida no es una imagen $»$ (Sicard, 1997: 46). 
que esas imágenes proveen modelos de la realidad cuando ésta última no es directamente accesible, se puede hablar del rol referencial de la imagen como sustituto congnitivo (o modelo) de una información perceptiva no disponible (Denis, 1989). Roland Barthes ha mostrado que la imagen publicitaria no posee más que una débil función icónica o de parecido ; es la función simbólica o semiótica de las imágenes la que permite evocar la representación de objetos o de acontecimientos, las imágenes mentales ${ }^{4}$ desarrollándose en el niño sobre la base de representaciones semióticas interiorizadas. La imagen de las modelos no es entonces simplemente ilustrativa, no es solamente un « indicio periférico agradable », para utilizar la fórmula de la steorías psicológicas del tratamiento de la información. Complejos argumentos figurativos (Scott, 1994), las imágenes publicitarias de las modelos juegan un rol clave en el marco del dispositivo persuasivo del anuncio. Pero la voluntad de parecerseles encierra a las mujeres destinatarias en la lógica limitante de la imitación: ellas no podrían ser «más que un pedazo de la mujer esencial» (Baudelaire, 1846) ...

Por lo tanto, las mujeres destinatarias se comparan con las modelos y los efectos de estas comparaciones ascendentes sobre la propia autoestima (Jones et Buckingham, 2005), la satisfacción corporal (Humphreys et Paxton, 2004) y el humor (Tiggeman et McGill, 2004) son a menudo negativos. De estas frecuentes comparaciones se puede llegar a distorsiones de la imagen del cuerpo (Groesz, Levine et Murnen, 2001) y conducir a enfermedades graves, como la anorexia o la bulimia (Furnham, Badmin et Sneade, 2002) ... La fuente de la insatisfacción corporal de las mujeres sería el decalaje percibido entre el sí mismo real (o actual) y el sí mismo ideal (la proyección de sí en el futuro, hecha de metas y de esperanzas) : los investigadores evocan hoy la dimensión « normativa » de la insatisfacción corporal (Brown y Dittmar, 2005: 1089) para subrayar el caracter general de una insatisfacción corporal moderada en las mujeres de las sociedades occidentales (Rodin et al., 1985 ; Feingold \& Mazella, 1998). Los medios de comunicación juegan ciertamente un rol importante en la transmisión y la legitimación de la norma de la belleza/ delgadez (Kilbourne, 1999 ; Thompsonyt Stice, 2001), pero su poder está reforzado por las influencias sociales múltiples y convergentes - la familia, los pares, la escuela, el mundo profesional, los especialistas de la salud, etc. (Levine y Smolak, 1996). No obstante, el impacto de las imágenes idealizadas de la belleza femenina está lejos de ser

7. ¿Cuales son las relaciones entre imágenes mentales y representaciones verbales ? Según la teoría pionera de Paivio (1971), « dos sistemas de codificación » $\mathrm{o} \ll$ modos de representación simbólica » son utilizados por el individuo : el sistema de las representaciones imaginadas es puesto en obra cuando el individuo debe tratar una información que tenga un contenido, mientras que el sistema de las representaciones verbales está especializado en el tratamiento del lenguaje. Pero un artículo publicado por Pylyshyn (1973) puso en cuestión la existencia de la doble codificación: las imágenes mentales y las representaciones verbales no son mediadores indispensables del pensamiento, sino más bien sus productos secundarios, de donde la idea de un «lenguaje del pensamiento ». En fin, según Kosslyn (1977), una parte de la información (sea ésta de origen figurativo o verbal) sería conservada en memoria de la misma manera, es decir bajo la forma proposicional. Las imágenes mentales serían así « representaciones analógicas », manteniendo una relación de correspondencia no arbitraria con los objetos representados. 
uniforme e unívoca (Champion y Furnham, 1999): todas las mujeres expuestas no desarrollan inevitablemente desórdenes alimenticios, algunas declaran incluso sentir placer al mirar esas imágenes (Polivy y Herman, 2004), particularmente cuando hay inspiración para imitar el modelo (Mills et al., 2002 ; Durkin y Paxton, 2002).

Con el fin de explicar la variabilidad de los efectos producidos por la exposición a las imágenes idealizadas de la belleza femenina, los investigadores han identificado y medido estos últimos años muchos factores mediadores esenciales: metas de la comparación social (Martin y Kennedy, 1993), la frecuencia de las comparaciones (Gibbons y Buunk, 1999)5), la claridad del concepto de sí (Stice, 1994), el nivel de la autoestima (Grogan, Williams y Conner, 1996), la depresión (Cash y Smith, 1982). Los psicólogos sociales han igualmente puesto en evidencia el rol moderador de la internalización de la norma de la belleza/ esbeltez en el impacto de las comunicaciones mediáticas (Brown et Dittmar, 2005 ; Dittmar y Howard, 2004). Si las comparaciones ascendentes con las modelos aumentan la ansiedad de las mujeres destinatarias que posean un elevado nivel de internalización de la norma belleza/ esbeltez, las mujeres destinatarias que poseen un nivel débil de internalización de esta norma no serían afectadas más que levemente (Halliwell y Dittmar, 2004). Algunos acercamientos cognitivos han examinado los efectos de la activación del esquema « apariencia física » en la recepción de los mensajes focalizados sobre el atractivo físico (Hargreaves y Tiggemann, 2002) insistiendo sobre el vínculo con el concepto de sí. El esquema de la apariencia física es una estructura cognitiva que organiza y determina el tratamiento de las informaciones vinculadas con el yo, relativas a la apariencia física (Cash y Labarge, 1996). En ese contexto, las modelos son estímulos percibidos como pertinentes para el esquema de la apariencia física y son entonces susceptibles de conducir a la activación de ese esquema cuando se exponen a los medios de comunicación. Esta activación tendría consecuencias cognitivas y afectivas diversas, en función del contenido y de la complejidad de los esquemas de la apariencia física de las mujeres destinatarias (Hargreaves y Tiggemann, 2002). Una correlación positiva ha sido identificada entre la existencia de esquemas de la apariencia física complejos y la internalización de la norma

8. Las comparaciones frecuentes pueden ser peligrosas para uno. Estudios han puesto en evidencia una correlación positiva entre la tendencia a compararse frecuentemente en el plano de la apariencia física y una satisfacción corporal reducida, así como problemas del comportamiento alimenticio. En regla general, los individuos desdichados, depresivos o con una débil autoestima se comparan muy a menudo con los otros. Así, los individuos cuyas señales internas se perturban serán más susceptibles de comprometerse frecuentemente en comparaciones sociales con el fin de disminuir su estado de incertidumbre o inseguridad (Gibbons et Buunk, 1999; Giordano, Wood et Michela, 2000). Los individuos dependientes de la opinión de los otros, a la vez impacientes y deseosos de seducir, estarán preocupados por responder a las expectativas relativas a la apariencia física, mientras que los individuos independientes, más autónomos con relación al dictamen de los otros, serán menos sensibles a la evaluación de su entorno (Jodelet, 1994). Esta diferencia interindividual se realiza al mismo tiempo que el uso diferencial de la comparación social: si los dependientes se comparan a menudo, los independientes lo hacen más raramente y buscan menos la aceptación social. 
belleza/ esbeltez (Labarge, Cash y Brown, 1998). Así, las mujeres para las cuales la belleza es un atributo central de la definición de sí mismas son más vulnerables a las comparaciones ascendentes que las mujeres que le dan un lugar periférico al atractivo físico en su esquema de sí mismas. (Patrick, Neighbors y Knee, 2004).

A partir del artículo fundador de Festinger (1954), numerosas investigaciones han remarcado la importancia de los procesos de comparación social en la génesis y la transformación de la imagen del cuerpo (Wheeler y Miyake, 1992). ¿Cómo explicar el hecho de que, en ciertas situaciones, las mujeres confrontadas a imágenes idealizadas de belleza femenina, efectúan autoevaluaciones negativas, mientras que, en otras situaciones, las mismas mujeres, confrontadas a los mismos modelos, sean susceptibles de efectuar autoevaluaciones positivas de su propio atractivo físico ? Estudios recientes sugieren que el proceso responsable de este efecto contrastado sería el anclaje cognitivo de la comparación (Lockwood, 2002 ; Mussweiler y Strack, 2000 ; Stapel y Koomen, 2000): cuando las mujeres destinatarias utilizan a modelos como puntos de referencia para la autoevaluación, esta comparación ascendente conduciría a un efecto de contraste (impacto negativo sobre la imagen del cuerpo) ; cuando las mujeres destinatarias piensan que la dimensión de comparación - la esbeltez - es relativamente maleable y que es posible acercarse al modelo, esta comparación ascendente conduciría a un efecto de asimilación (impacto positivo en la imagen de sí).

Unas veces buscada e iniciada de manera autónoma, otras veces impuesta socialmente, la comparación social se pone en acto a través de estrategias de comparación variadas, motivadas sea por la incertidumbre en cuanto a sus características personales (fin de autoevaluación), sea por la voluntad de mejorarlas (fin de mejoramiento), sea enfin por la necesidad de afirmar su propósito (meta de reafirmación de sí). Pero las comparaciones sociales focalizadas en los atributos importantes para sí constituyen a la vez una fuente preciosa de informaciones y un momento delicado de negociación identitaria (Codol, 1975). Las mujeres destinatarias deben entonces equilibrar de la mejor manera posible, según el contexto, el deseo de gustar (conformismo social) y, respectivamente, la voluntad de preservar su unicidad (diferenciación social). De hecho, más que pensar que habría en las mujeres destinatarias una necesidad de evaluar su apariencia física, ¿no sería más factible pensar que ellas tendrían a veces una necesidad de no evaluarla? (Goethals, 1986). Ya que es legítimo constatar que, a veces, los individuos no desean conocer « la verdad » sobre ellos mismos a través de una autoevaluación rigurosa, sino que desean que otro valide sus características personales. Pues la autoevaluación puede ser costosa en el plano identitario. Según Brickman y Bulman (1977), los individuos son motivados tanto para evitar la comparación social como para buscarla. Si las motivaciones adaptativas conducen al individuo a buscar la comparación con el fin de obtener informaciones necesarias para una mejor integración social, las motivaciones narcisísticas conducen al contrario a evitar la comparación a fin de preservar su autoestima y un humor positivo... Cuando la presión a favor de la adaptación es dominante, una meta de comparación superior es buscada, y cuando la presión narcisística es dominante, una meta inferior es preferida, pues es 
susceptible de acrecentar el bienestar y de contribuir al refuerzo de la autoestima (ibid. : 179). Cuando el objetivo de comparación prevista es la autoevaluación, la comparación ascendente sería a menudo buscada por las mujeres destinatarias de los mensajes sobre la belleza, pero cuando se trata de la protección o del aumento de la autoestima, la comparación descendente será preferida. Entonces, más que hablar de la comparación social en singular, habría quizás que señalar la doble cara de la comparación social (Willis, 1986), la tendencia a la autoevaluación competiría a veces con la tendencia a la autovalidación. Lejos entonces de ser un proceso único, modelable exclusivamente a partir de la autoevaluación, la comparación social aparece como un conjunto de estrategias orientadas por los fines del individuo observador, y donde el registro último es identitario ${ }^{6}$. La comparación ascendente (con una meta superior), la comparación lateral (con una meta similar) o la comparación descendente (con una meta inferior) serán todas susceptibles de ser buscadas, cada una a su turno, en función de la meta perseguida por el individuo observador - autoevaluación, reafirmación de sí, o mejoramiento. Estrategias motivadas, las mujeres aparecen así no como sujetos pasivos que « sufren» los procesos de comparación social con las modelos, sino como agentes que utilizan las estrategias de comparación social que les permite, en cierta medida fabricar o ignorar la realidad social (Goethals, 1986), en función de metas definidas.

\section{Estudio experimental}

La mayor parte de los investigadores que han estudiado las consecuencias de la exposición a los modelos de belleza presentados por los medios de comunicación han discutido los efectos de la comparación social partiendo de la premisa implícita de que la meta perseguida por las mujeres destinatarias sería la autoevaluación de la apariencia física. Investigaciones recientes (Martin y Kennedy, 1994 ; Gentry et al., 1996) han sin embargo demostrado que las mujeres destinatarias miran a veces esas imágenes con un objetivo de mejoramiento de la apariencia física, de reforzamiento de sí o de autovalidación.

La publicidad para productos cosméticos adelgazantes presentados en las revistas femeninas celebran la belleza/ esbeltez a través de la puesta en escena de bellezas ideales, a menudo percibidas como inaccesibles. La comparación ascendente corre el riesgo de conducir a las mujeres destinatarias a efectuar inferencias negativas relativas a la eficacia supuesta del

9. Hakmiller (1966) es a menudo citado como el que ha efectuado la demostración clásica de « la comparación social descendente en situación de amenaza» : ha demostrado que cuando la autoevaluación de una característica personal es percibida « amenazante para uno mismo » (sentimiento de inferioridad activa para una comparación ascendente), el individuo busca una meta de comparación inferior, en una meta de protección o reforzamiento de sí. Si la comparación ascendente efectuada en una meta de autoevaluación es una fuente de informaciones ricas en el plano evaluativo, la comparación descendente efectuada con un fin de protección o de reforzamiento de sí es en principio valorizante para uno. 
producto (expectativa en el resultado) y a la eficacia personal en la utilización de cuidado para combatirla celulitis (auto-eficacia).La puesta en escena alternativa de « mujeres medianamente atractivas » (comparación lateral) o « poco atractivas » (comparación descendente) podría ser una solución a la vez menos nociva para el humor y la satisfacción personal de las mujeres destinatarias, y más persuasiva, pues favorece la identificación a través de una similaridad percibida entre uno y la modelo (Bandura, 1977). En efecto, si para las mujeres que no se sienten particularmente concernidas por los problemas de peso o de celulitis, los productos cosméticos adelgazantes son productos embellecedores « como los otros » (implicación débil), por otra parte, para las mujeres que piensan tener dificultades de peso o de celulitis, los productos cosméticos adelgazantes pueden convertirse en una solución que permite afrontar una situación de disconformidad personal (implicación fuerte). Para la primera categoría de mujeres, la comparación ascendente con las modelos femeninas es potencialmente menos peligrosa para sí mismas que para la segunda categoría de mujeres destinatarias. Por otra parte, en el plano argumentativo, la publicidad para productos cosméticos adelgazantes pone por delante los beneficios de una utilización regular de los productos presentados. No obstante, según las teorías del tratamiento de la información (Petty, 1997 ; Petty y Wegener, 1999; Chaiken, Liberman y Eagly, 1989), insistir en las ganancias a través de un marco positivo sería eficaz cuando la implicación de las mujeres destinatarias es débil, mientras que cuando la implicación es fuerte, es la puesta en evidencia de los riesgos por un marco negativo la que se manifiesta más convincente (Maheswaran y Meyers-Levy, 1990).

Hemos realizado un estudio experimental en recepción con la finalidad de medir el impacto de las estrategias icónicas de comparación social (ascendente $v s$ lateral $v$ s descendente) y del marco argumentativo (positivo $v$ negativo) sobre las emociones y las cogniciones de las mujeres destinatarias de una publicidad para productos cosméticos adelgazantes, según su nivel de implicación (fuerte $v$ débil) en relación a los problemas de peso. La investigación se realizó en la primavera de 2003 en la universidad Paris III - Sorbonne Nouvelle, con un corpus de 221 estudiantes de entre 20 y 25 años. En una primera etapa, inducimos un nivel de implicación diferente con relación a los problemas de peso: elaboramos dos variantes del mismo comunicado científico, atribuido al INSERM ${ }^{7}$ (fuente competente, confiable), y se expuso a la mitad de la muestra a una de las versiones, mientras que la otra mitad leía la segunda versión. La primera variante, destinada a desplazar temporalmente la norma de peso en una dirección desfavorable a los sujetos, informaba que en Francia las mujeres jóvenes de entre 20 a 25 años «tienen un peso normal de alrededor de 50 kilos $»^{8}$. La segunda variante del comunicado, destinado a reforzar la norma de peso en un sentido favorable a los sujetos, mencionaba que ese peso normal sería de « alrededor de $58 \mathrm{~kg}$ ». Las dos versiones recordaban

10. Instituto Nacional de la Salud y de la Investigación Médica. (N. del T.)

11. Según las cifras del INSEE (Instituto Nacional de la Estadística y de los Estudios Económicos), el peso medio de las mujeres en Francia en esa fecha era de 58-60 kilos, $c$ f. www.insee.fr. 
en términos idénticos las consecuencias nefastas del sobrepeso en la salud y eran presentadas (sin excepción) acompañadas por otros dos comunicados, éstos auténticos: un comunicado del INVS 9 relativo a las consecuencias del SIDA y un comunicado del INSEE vinculando los efectos negativos del tabaco en la salud. La modificación de la implicación situacional (orientación temporal con respecto al producto) estaba destinada a actuar sobre las metas de comparación de las mujeres destinatarias: los sujetos expuestos al comunicado sobre el peso normal de $50 \mathrm{~kg}$ irían a mirar la publicidad para productos cosméticos adelgazantes en una óptica de « búsqueda de soluciones » o de mejoramiento, es decir de preservación defensiva de la autoestima (situación de fuerte implicación); los sujetos expuestos al comunicado en relación al peso normal de $58 \mathrm{~kg}$ mirarían la publicidad para productos cosméticos adelgazantes con un objetivo de autoevaluación o de embellecimiento - mejoramiento (implicación débil). En una segunda etapa, fueron expuestos a una publicidad de un nuevo producto cosmético adelgazante, del que no se mencionaba la marca con el fin de evitar inclinaciones evaluativas. Construimos seis anuncios diferentes : tres visuales « mujer $\gg$ fueron asociados sistemáticamente con el marco positivo del gancho y, respectivamente, en el marco negativo, el texto argumentativo era idéntico. Los tres « mujer visual » permitían operacionalizar los tres tipos de comparación social : ascendente (visual « mujer muy atractiva »), lateral (visual $\ll$ mujer medianamente atractiva $\gg$ ) y descendente (visual « mujer poco atractiva $\gg)^{10}$. El marco argumentativo de los ganchos fue positivo en tres de los anuncios y negativo en los otros tres. Para resumir, doce grupos independientes de quince a veinte jóvenes estudiantes fueron cuestionados. La duración total del ejercicio (primera y segunda fase) fue de entre 2025 minutos. Al término de la experimentación, los investigadores develaban a los sujetos el verdadero objetivo de la investigación.

Los resultados que se obtuvieron con el tratamiento estadístico de los datos (análisis de varianza) varían según el nivel de implicación de las mujeres destinatarias. Para los sujetos con problemas de peso, la puesta en escena de una «mujer medianamente atractiva », favoreciendo una comparación lateral, tiene un mejor impacto en las creencias de eficacia y la intención comportamental. Por otro lado, para los sujetos sin problemas de peso, la puesta en escena de una « mujer muy atractiva $»$, favoreciendo una comparación ascendente, conduce a un impacto más fuerte sobre las creencias de eficacia y la intención comportamental. Para esta segunda categoría de mujeres, la distancia percibida entre sí y la mujer del anuncio no es vista

12. Instituto de Vigilancia Sanitaria.

13. La elección de lo visual se hizo utilizando el "procedimiento de los jueces", en este caso pedimos a 30 estudiantes observar siete fotografías de mujeres (dónde se podían ver las partes del cuerpo presentadas habitualmente por la publicidad para productos cosméticos - caderas, nalgas, muslos). Debieron jerarquizar estas fotografías según el criterio "belleza/esbeltez" (la pregunta formulada era “icual, entre estas mujeres, es la más bonita y la más fina?” "; una vez hecha la elección, la pregunta se repetía, hasta que no hubieran más fotografías).” Las tres fotografías elegidas son las que fueron elegidas más frecuentemente en primera posición (para la comparación ascendente), en medio de la clasificación (para la comparación lateral) y en última posición (para la comparación descendente). 
como inabordable, la modelo era mirada como un buen argumento en favor de la eficacia del producto y de las recomendaciones - expectativa de resultado, y como una prueba de eficacia personal en el camino del embellecimiento - auto-eficacia (Bandura, 1977, 1989). Pero para las mujeres que se piensan concernidas por problemas de peso y/o de celulitis, es la contemplación de una « mujer medianamente atractiva $\gg$ la que favorece la mejor identificacion. Para este tipo de sujetos, una mujer « medianamente atractiva » credibiliza el producto y el mensaje, refuerza la confianza en sí e incita a utilizar el cuidado propuesto - efectos positivos de comparación lateral sobre la auto-eficacia, la expectativa del resultado y la intención conmportamental : «Yo probaría ese producto $\gg, ~ «$ Quizás sería necesario que yo probara ... », « Si es verdad, lo compro », «El producto suena tentador », « Ahora que leí el texto, yo compraría el producto » ...

Para las mujeres que se consideran poco concernidas por los problemas de peso, la imagen de una «mujer poco atractiva » (comparación descendente) conduce a una intención comportamental de compra tan fuerte como la imagen de una « mujer muy atractiva » Una explicación posible para este efecto sorpresa sería que el miedo moderado suscitado por esta imagen poniendo en escena el « peligro » de la celulitis es susceptible de aumentar el interés de las mujeres débilmente implicadas en relación a los cuidados adelgazantes. Con el fin de preveer ese « peligro », ellas estiman que es necesario tomar medidas preventivas rápidas y apropiadas: « Es demasiada horrible la celulitis. ¿Por qué no probar este producto ?», « No hay que conservar este horror sobre sí, entonces, rápido, hagan algo», « Celulitis: pesadilla de todas las mujeres. Yo quiero ese producto ${ }^{11}$...

Para concluir, somos parte de la premisa de que la utilización publicitaria de la comparación social ascendente no permite siempre a las mujeres destinatarias de productos cosméticos adelgazantes creer en su propia capacidad de alcanzar la meta belleza / esbeltez-, y adelantamos la hipótesis que la puesta en escena alternativa de las mujeres « medianamente atractivas » o « atractivas » sería susceptible de reforzar la creencia de auto-eficacia de las mujeres destinatarias en situación de fuerte implicación (o de amenaza), ya que en ésta situación, las mujeres leen el anuncio con el fin de encontrar informaciones que les permiten remediar el problema percibido en su apariencia física, mientras que en situación de escasa implicación las mujeres leen el anuncio con el fin de encontrar informaciones que les permiten embellecerse aún más... Los objetivos de comparación activados serían diferentes: la mejora o el aumento de sí en situación de fuerte implicación vs la autoevaluación o la mejora de sí en situación de escasa implicación. La activación de estos objetivos conduce a las mujeres destinatarias a preferir algunos objetivos de comparación y a evitar otros: en situación de fuerte implicación, prefieren enfrentarse a mujeres percibidas como similares o menos bonitas (comparación lateral o descendente), mientras que en situación de escasa implicación buscan la comparación ascendente (modeling), o incluso la comparación descendente (contraste positivo).

14. Radu, M. (2006) « La comparación social con las mujeres maniquíes: ¿̇un cara a cara estimulante o peligroso? “, Marketingy comunicación, 1(1), 56-70. 


\section{La belleza femenina: el género como encrucijada identitaria}

Los medios de comunicación participan hoy ampliamente en la construcción, la difusión y la legitimación de un sistema normativo basado en una definición limitada de la belleza femenina como esbeltez. El estudio de los efectos en recepción de los anuncios publicitarios permite entender cómo las mujeres destinatarias se posicionan con relación a los modelos femeninos, cómo administran a nivel cognoscitivo y emocional la comparación ascendente con las modelos, cómo reciben, interpretan e integran las propuestas de sentido mediáticas, y con qué efectos sobre sí. Este enfoque de cognición situado concibe a las mujeres destinatarias de los discursos sobre la belleza como inscritas situacionalmente y portadoras de creencias, expectativas, competencias lingüísticas y comunicacionales, como doblemente situadas, por lo tanto, a la vez con relación a lo social y con relación a los objetos y a las situaciones. De ahí la necesidad de un trabajo de comprensión y análisis de las sociedades en las cuales las cogniciones sobre la belleza se forman y se transforman, y de los mismos mensajes publicitarios, que "al hablar del mundo lo reinventan”, para parafrasear la expresión de Hagège (1985). En efecto, la belleza femenina pone en juego lo identitario que implica a la vez la definición sí de la mujer y su definición social. En este sentido, la recepción de las comunicaciones mediáticas teniendo por objeto explícito el cuerpo femenino sería un momento clave de negociación idéntitaria de género.

Ciertamente, las mujeres destinatarias del discurso publicitario sobre la belleza/esbeltez no son enteramente libres, en el sentido en que ningún individuo que vive en sociedad tiene acceso a una libertad desprovista de toda dificultad, puesto que normas, valores, hábitos guian nuestras acciones, nuestras palabras, nuestros deseos propios. Pero su libertad, pueden conquistarla a través de un reglamento sutil de los objetivos de comparación contemplados: desear no autoevaluarse sistemáticamente con relación a los modelos de belleza, sino más bien mejorarse al producirse beneficio, o incluso tranquilizarse a través de la búsqueda de una comparación descendente - serían quizá vías abiertas hacia la serenidad y la aceptación armoniosa de sí (Fister et Smith, 2004). Enseñar a las jóvenes muchachas, a partir de la escuela, las estrategias beneficiosas para sí de la comparación social, sería darles medios de conquistar su libertad: frágil, incompleta, inestable, pero libertad sin embargo ante el discurso omnipresente de la perfecta belleza...

\section{Referencias bibliográficas}

Bandura, A. (1977). « Self-efficacy : Toward a Unifying Theory of Behavioral Change $»$, Psychological Review, 84, 191-215.

Bandura, A. (1989). « A Social Cognitive Theory of Action », Ed. J.P. Forgas et J.M. Innes, Recent Advances in Social Psychology: An International Perspective. North-Holland : Elsevier Science Publishers, 127-138. 
Baudrillard, J. (1970). La société de consommation. Paris : Gallimard.

Bernard, M. (1995). Le corps. Paris : Editions du Seuil.

Brickman, P. et R.J. Bulman (1977). « Pleasure and pain in social comparison », Ed. J.M. Suls et R.L. Miller, Social comparison processes: Theoretical and empirical perspectives. Washington: Hemisphere, 149-186.

Brown, A. et Dittmar, H. (2005). « Think « thin » and feel bad : the role of appearance schema activation, attention level, and thin-ideal internalization for young women's responses to ultrathin media ideals $\gg$, Journal of Social and Clinical Psychology, 24(8), 1088-11 13.

Chabrol, C. (1971). Le récit féminin. Contribution à l'analyse sémiotique du courrier de coeur dans les entrevues ou « enquêtes » sur la femme dans la presse féminine actuelle. La Haye/Paris : Mouton.

Chaiken, S. A. Liberman et A.H. Eagly (1989). «Heuristic and systematic information processing within and beyond the persuasion context», Ed. J. Uleman et J.A. Bargh, Unintended thoughts. New York: The Guilford Press, 212-252.

Codol, J.P. (1975). « On the so-called « superior conformity of the self » : Twenty experimental investigations », European Journal of Social Psychology, 5, 457-450.

Denis, M. (1989). Image et Cognition. Paris : Presses Universitaires de France.

Dittmar, H. et S. Howard (2004). « Thin-ideal internalization and social comparison tendency as moderators of media models' impact on women's body-focused anxiety », Journal of Social and Clinical Psychology, 23(6), 768-791.

Dolto, F. (1961). «Personnologie et image du corps », in La psychanalyse, vol. 6. Paris : Preses Universitaires de France.

Dolto, F. (1984). L'image inconsciente du corps. Paris : Editions du Seuil.

Engeln-Maddox, R. (2005). « Cognitive responses to idealized media images of women: the relationship of social comparison and critical processing to body image disturbance in college women», Journal of Social and Clinical Psychology, 24(8), 1114-1138.

Fister, S.M. et G.T. Smith (2004). « Media effects on expectancies: exposure to realistic female images as a protective factor $\gg$, Psychology of Addictive Behaviors, 18(4), 394-397.

Furnham, A., N. Badmin et I. Sneade (2002). « Body image dissatisfaction : gender differences in eating attitudes, self-esteem, and reasons for exercice», The Journal of Psychology, 136(6), 581-596.

Gentry, J.W. et al. (1996). « Gender and Age Differences in the Importance of Physical Attractiveness : Advertising Presentations and Motives for Comparison for Pre-Adolescent Children », Ed. J.A. Costa, Proceeding of the Third Conference on Gender, Marketing, and Consumer Behavior. Salt Lake City, UT : University of Utah Printing Service, 1-15.

Gibbons, F.X. et B.P. Buunk (1999). « Individual differences in social comparison : Development of a scale of social comparison orientation », Journal of Personality and Social Psychology, 76, 129142.

Giordano, C. et al. (2000). « Depressive personality styles, dysphoris, and social comparisons in everyday life $\gg$, Journal of Personality and Social Psychology, 79, 438-451.

Goethals, G.R. (1986). « Social Comparison Theory : Psychology from the Lost and Found», Personality and Social Psychology Bulletin, 12(3), 261-278.

Goethals, G.R. (1986). « Fabricating and ignoring social reality: Self-serving estimates of consensus», Ed.J.M. Olson, C.P.Herman et M.P.Zanna, Relative deprivation and social comparison: The Ontario Symposium. Hillsdale, New Jersey: Lawrence Erlbaum, 135-158. 
Groesz, L.M. et al. (2002). « The effect of experimental presentation of thin media images on body satisfaction: a meta-analytic review», International Journal of Eating Disorders, 31(1), 1-16.

Hakmiller, K.L. (1966). « Threat as a determinant of downward comparison », Journal of Experimental Social Psychology, 2, 32-39.

Halliwell, E. et H. Dittmar (2004). « Does size matter ? The impact of model's body size on women's body-focused anxiety and advertising effectiveness », Journal of Social and Clinical Psychology, 23(1), 104-122.

Humphreys, P. et S.J. Paxton (2004). « Impact of exposure to idealised male images on adolescent boys' body image $\gg$, Body image, 1, 253-266.

Jodelet, D. (1994). « Le corps, la personne et autrui », Dir. S. Moscovici, Psychologie sociale des relations à autrui. Paris : Editions Nathan.

Jones, A.M. et J.T. Buckingham (2005). «Self-esteem as moderator of the effect of social comparison on women's body image », Journal of Social and Clinical Psychology, 24(8), 1164-1187.

Kosslyn, S.M. et J.R. Pomerantz (1977). « Imagery, propositions and the form of internal representations», Cognitive Psychology, 9, 52-76.

Lauzon, J. (2000). « La photographie fille de l'alchimie », Horizons philosophiques, 11(1).

Le Breton, D. (1990). Anthropologie du corps et modernité. Paris : Presses Universitaires de France.

Lipovetsky, G. (1983). Lè̀re du vide. Essai sur l'individualisme contemporain. Paris : Gallimard.

Maheswaran, D. et J. Meyers-Levy (1990). « The Influence of Message Framing and Issue Involvement », Journal of Marketing Research, 27, 361-367.

Markey, C.N. et P.M. Markey (2005). « Relations between body image and dieting behaviours: an examination of gender differences $\gg$, Sex roles, 53(7/8), 519-530.

Martin, M.C. et P.F. Kennedy (1993). « Social Comparison and the Beauty of Advertising Models: The Role of Motives for Comparison $\gg$, Advances in Consumer Research, 21, 365-371.

Noles, S.W., T.F. Cash et B.A. Winstead (1985). « Body image, physical attractiveness, and depression $\gg$, Journal of Consulting and Clinical Psychology, 53(1), 88-94.

Paivio, A. (1971). Imagery and verbal process. New York: Holt, Rinehart \& Winston.

Perrot, P. (1984). Le travail des apparences. Le corps féminin. XVIIIe-XIXe siècles. Paris : Editions du Seuil.

Petty, R.E. (1997). « The Evolution of Theory and Research in Social Psychology : From Single to Multiple Effects and Process Models of Persuasion », Ed. G. Garty et S.A. Mc Haslam, The message of social psychology. Cambridge: Blackwell Publishers, 268-290.

Petty, R.E. et D.T. Wegener (1999). « The Elaboration Likelihood Model : Current Status and Controversies », Ed. S. Chaiken et Y. Trope, Dual-Process Theories in Social Psychology. New York: The Guilford Press, 41-72.

Polivy,J.et Herman, C.P. (2004). «Socioculturalidealization of thin female body shapes: an introduction to the special issue on body image and eating disorders $\gg$, Journal of Social and Clinical Psychology, 23(1), 1-6.

Pylyshyn, Z.W. (1973). «What the mind's eye tells the mind's brain : A critique of mental imagery », Psychological Bulletin, 80, 1-25.

Radu, M. (2006) « La comparaison sociale avec les femmes mannequins : un face à face stimulant ou dangereux? », Marketing et communication, 1(1), 56-70.

Raveneau, G. (2000). « Une nouvelle économie du corps : bien-être, narcissisme et consommation », 
Sociétés, 69, 19-32.

Scott, L.M. (1994). «Images in Advertising : The Need for a Theory of Visual Rhetoric », Journal of Consumer Research, 21, 252-273.

Sicard, M. (1997). « Les paradoxes de l'image », Hermès, 21, 45-54.

Vacker, B. (1993). « Beauty and the Beast (of advertising) », Advances in Consumer Research, 20, 245351.

Wills, T.A. (1986). « Discussion Remarks on Social Comparison Theory », Personality and Social Psychology Bulletin, 12(3), 282-288.

Willis, T.A. (1981). « Downward comparison principles in social psychology », Psychological Bulletin, 90, 245-271. 